\title{
Students' Self and Group-Driven Motivation on Target-Oriented Activity in Grammar Learning
}

\author{
Hairus Salikin ${ }^{1}$, Saidna Zulfiqar Bin-Tahir ${ }^{2}$, Hari Supriono ${ }^{1} \&$ Anisya Rahmawati ${ }^{1}$ \\ ${ }^{1}$ English Department, Faculty of Humanities, Universitas Jember, Indonesia \\ ${ }^{2}$ English Education Department, Universitas Iqra Buru, Maluku, Indonesia \\ Correspondence: Saidna Zulfiqar Bin-Tahir, English Education Department, Universitas Iqra Buru, Maluku, \\ Indonesia, Jl. Prof. Dr. Abdurrahman Basalamah, Namlea, Ambon. E-mail:saidnazulfiqar@gmail.com
}

Received: April 22, 2018 Accepted: May 17, 2018 Online Published: June 9, 2018

doi:10.5539/ijel.v8n5p192 URL: https://doi.org/10.5539/ijel.v8n5p192

\begin{abstract}
The article investigated students' self and group-driven motivation in learning Grammar \& Structure 03 on target oriented activity. It aimed at exploring what factors influence the participants and their higher motivation between self and group-driven motivation are, and how their motivation progress is toward the target-oriented activity. This article applied three phases of motivation theory (Dornyei and Otto, 1998) and language learning strategies (Dornyei, 2005). The results show that self-motivation is more dominant than group-driven motivation. Several factors influenced the motivational components which inhibit and enhance motivation on task. Considering the learning strategies, the participants tend to be more effective by subjective values and norms, however, emphasizing the task, they can manage both motivation types to be interdependence. Moreover, the participants' motivation stages show that group-driven motivation progress is capable of enhancing motivation. Whereas, the downward scale of self-motivation as the result of the motivational disposition failed in generating enactment.
\end{abstract}

Keywords: motivation stage, self-motivated learner, group-driven motivated learner

\section{Introduction}

\subsection{Introduce the Problem}

Motivation research has been done almost three decades that it has become a significant issue in language learning (Dornyei, 2005; Brown, 2007; Dollah, 2016; Salikin et al., 2017). Motivation is a talented, dynamic, and complex phenomenon which intrinsically and extrinsically affects the language learners. Besides, it is complexly delineated by many components which have its role in its process. Therefore, motivation research cannot be explained in the brief discussion. As a complex and significant factor in learning English, this research observes the case of motivation progress into two types of motivation, Self-motivation and group-driven motivation. In emphasizing the target-oriented activity, a weekly group assignment experience is a vein of this research to see how the motivation progress of English Department students in learning Grammar \& Structure 03.

Motivation itself is an impetus or desire of individuals to achieve something. It can be formed as the feeling of need that must be fulfilled. This also can be described as the learners' feeling to become or behave productively active in learning L2. This case can be influenced by inside and outside aspects of the learners as the factor can be found in any situation of learning in which, every human being has the motivation to every single thing, especially, to be a learner of language (Brown, 2007).

Language learners can highly motivate themselves before and after, during their process of English learning in the college. Different learning structure between high school and college can affect the learners in which they have the different levels of motivation gather together to solve some tasks (Bin-Tahir \& Rinantanti, 2016; Patahuddin et al., 2017; Salikin et al., 2017). This kind of situation usually happens if they are in the group, for example, a group assignment, a classmate. Emphasizing the group in society, it assumed if learners interact each other; their motivation can be fluctuant according to a particular situation (Dornyei, 2005; Tahir \& Hanapi, 2017).

A group of friends in learning can be defined as the motivation factors. Those can probably occur mostly in the classroom. Additionally, the motivation that is caused by a group can be named as a group-driven motivation that 
is described as having insecure and low on self-efficacy which can only manage with a group of friends. Then, they can work as a group and can be motivated by the support of their group. On the contrary, the learners can also be identified as having a self-motivation. It is usually described as independent and discipline. Moreover, having good self-esteem and a good self-efficacy are also their characteristics.

Considering the process of motivation that is somehow a dynamic process on both motivation types, self and group-driven motivation, this process is respected as the ever-changing process. Dornyei and Otto's theory (1998) in Dornyei (2005) divides motivation into the three stages of motivation. They are a pre-actional stage, actional stage, and post-actional stage. In respect to the desires and wishes that are transformed into the three concepts of the process. Goals are the first thing which influences motivation. It is needed to be generated because the motivational dimension is based on the awareness that the individual will pursue. This is called a pre-actional stage. It is influenced by many factors such as, various goal properties, the value associated with the learning process itself (outcomes and consequences), attitudes towards the L2 and its speakers, the expectancy of success and perceived coping potential, learner beliefs and strategies, and the last environmental support (Dornyei, 2005).

The second is an actional stage. This stage of motivation refers to the intention of the goals. It is the learners' management to their purpose to the goals in the particular action. This motivational dimension describes the process of learners in studying L2. It can be concluded that the process on the actional stage mostly happens in the classroom. Learning L2 can be influenced by classroom setting, teachers or lecturers, and target oriented activity that supports the learners in the learning process and knowledge and use of self-regulatory strategies (Dornyei, 2005).

The last is a post-actional stage. This stage stands for the action toward the intention. This stage is an evaluation process of learners in the motivational dimension. The process can be as the learner experiences. It will determine what kind of action that is to be the next enactment to the first stage. So, the post-stage would be attribution factors, self-concept beliefs, and received feedback, praise, and grades (Dornyei, 2005, p. 85).

In respect to the characteristics of the learners in learning language, learning strategies are crucial as well. Learning strategy commonly refers to a way that consciously aware chosen of alternatives to cope with situation and task. This is usually required according to the learners' needs. If we can conclude that learning strategies are an alternative learning way to the situation and tasks that reasonably choose to reach the standard result.

Based on the above background study, there are three questions needed to be answered in this research, as follows: 1) What factors influence self and group-driven motivation on target oriented activity? 2) Which motivation is more dominant between self-motivation and group-driven motivation of the participants? and 3) How is the motivation progress of the participants on target oriented activity?

\section{Method}

This research employed both quantitative and qualitative research approaches. The data of this study are in the form of the participants' responses containing both self and group-driven motivations in English learning. The participants are English learners who were collected from English Department students in Grammar \& Structure 03 of A class. This class was chosen by the researchers who classified the classes based on the classroom structure that applying target oriented activity. The A class applied target oriented activity. The lecturer of the course assigned a weekly task to conduct the class. She used one session to explain the material then gives the students a test for the next session where the students have to comprehend the material within a week. So, the students of the A class was chosen to be the participant.

Moreover, there are 26 students ( 3 males and 23 females) in the A class. All students are qualified to be the participants, and they voluntarily wanted to be the participants. They also have experience in a group assignment They were nineteen to twenty years old of Indonesian students who live in both rural and urban area. They were third-semester students. They had experience in English learning with a group, especially weekly group assignment. In other words, the participants experienced the target-oriented activity.

Moreover, the instrument of this research is a questionnaire which applies Likert scale to enable calculation. A questionnaire adapts the Attitude/Motivation Test Battery (AMTB) proposed by Gardner (2004). On the other hand, this research modifies some statements from Gardner (2004) to specify of motivation on target-oriented activity. Then, only 37 statements from 130 statements of AMTB are used by the researchers. The questionnaire is divided into 3 sections according to three phases of motivation.

The questionnaire uses the six-level Likert scale to give measurable value to the responses. The levels are: 
Table 1. The levels of the Likert scale

\begin{tabular}{ccc}
\hline The Levels & The codes & The weight \\
\hline Strongly Disagree & r1 & 1 \\
Moderately Disagree & r2 & 2 \\
Slightly Disagree & r3 & 3 \\
Slightly Agree & r4 & \multicolumn{2}{|c}{} \\
Moderately Agree & r5 & 5 \\
Strongly Agree & r6 & 6 \\
\hline
\end{tabular}

Next, after collecting the data, those data will be transferred to the coding procedure and to convert the participants' responses to numbers. Then, the result will be processed by using the formula:

$$
\mathrm{NP}=[(\mathrm{n} * 1)+(\mathrm{n} * 2)+(\mathrm{n} * 3)+(\mathrm{n} * 4)+(\mathrm{n} * 5)+(\mathrm{n} * 6)] / \mathrm{Tn}
$$

NP refers to the average result of respondents' scale. And $\mathrm{n} 1$ is the number of people who selected response. While ' $r$ ' represents the weighting of response, the sign ' $T n$ ' is the total respondents.

After determining the data, the analysis is about interpreting the data set by applying descriptive statistics. It helped the researcher summarizes the results by describing the general tendencies in the data and the overall spread of the score (Dornyei, 2007, p. 213). Then, the next analysis is to examine and interpret the phenomena that are found in the data by applying the theories.

\section{Results}

After the collecting data sections are finished, those data are transferred into tables and divided into two categories according to which they are on the motivation types. Those results will show the higher scale chosen by the participants in which indicating the factors are. The higher average scale refers to the participants' point of views about the motivation itself whether they are influenced by group or not.

From Table 2, 3 and 4, the meaning of letter ' $S$ ' with the number (S1, S2, etc.) represents the number of the statement for 1 to 4 and so on of the questionnaire. Besides, the sign 'S8'in Table 2 shows the sign minus (-) that means a negative statement for self-motivation. Here, the statement shows the opposite value to self-motivation' point. The weight of the scale of a strong agreement refers or leads to the low self-motivation. This negative statement is only applied to the statement number 8 .

Table 2. The pre-actional stage of the participants

\begin{tabular}{ccc}
\hline No. & The statement numbers & The average scales \\
\hline 1 & S1 & 1.3 \\
2 & S2 & 2.76 \\
3 & S3 & 2.61 \\
4 & S4 & 4.46 \\
5 & S5 & 2.5 \\
6 & S6 & 1.76 \\
7 & S7 & 3.88 \\
8 & S8 (-) & 5.12 \\
9 & S9 & 5.34 \\
10 & S10 & 4.26 \\
11 & S11 & 3.53 \\
12 & S12 & 4.19 \\
13 & S13 & 3.8 \\
14 & S14 & 2.92 \\
15 & S15 & 3.34 \\
16 & S16 & 3.57 \\
17 & S17 & 3.8 \\
18 & S18 & 3.73 \\
\hline
\end{tabular}


Table 3. The actional stage of the participants

\begin{tabular}{ccc}
\hline No. & The statement numbers & The average scales \\
\hline 1 & $\mathrm{~S} 19$ & 1.3 \\
2 & $\mathrm{~S} 20$ & 2.76 \\
3 & $\mathrm{~S} 21$ & 2.61 \\
4 & $\mathrm{~S} 22$ & 3.15 \\
5 & $\mathrm{~S} 23$ & 2.5 \\
6 & $\mathrm{~S} 24$ & 1.76 \\
7 & $\mathrm{~S} 25$ & 4.23 \\
8 & $\mathrm{~S} 26$ & 4.42 \\
9 & $\mathrm{~S} 27$ & 5.34 \\
10 & $\mathrm{~S} 28$ & 3.46 \\
11 & $\mathrm{~S} 29$ & 3.8 \\
\hline
\end{tabular}

Table 4 . The post-actional stage of the participants

\begin{tabular}{ccc}
\hline No. & The statement numbers & The average scales \\
\hline 1 & $\mathrm{~S} 30$ & 4.61 \\
2 & $\mathrm{~S} 31$ & 3.84 \\
3 & $\mathrm{~S} 32$ & 3.88 \\
4 & $\mathrm{~S} 33$ & 3.96 \\
5 & $\mathrm{~S} 34$ & 3.96 \\
6 & $\mathrm{~S} 35$ & 4.76 \\
7 & $\mathrm{~S} 36$ & 2.15 \\
8 & $\mathrm{~S} 37$ & 3.42 \\
\hline
\end{tabular}

Moreover, the average scales of three phases motivation stages of the participants on self and group-driven motivation toward target oriented activity. The scales show the weight levels from 1 to 6 of Likert scale.

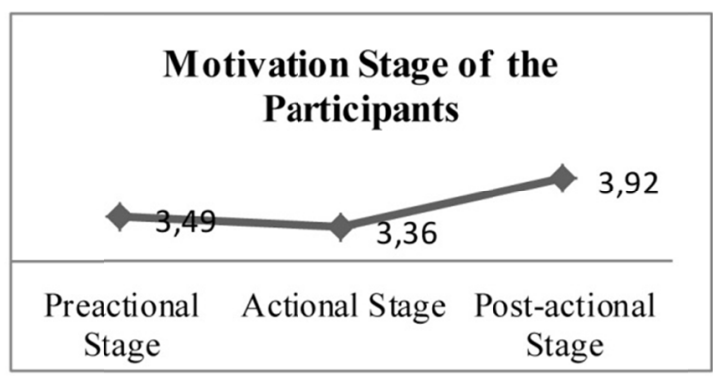

Diagram 1. The motivation stage in three phases of motivation of the participants

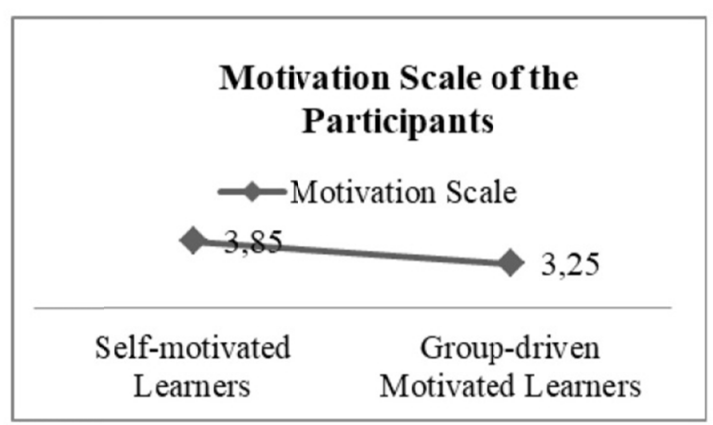

Diagram 2.The self and group-driven motivation scales of the participants 


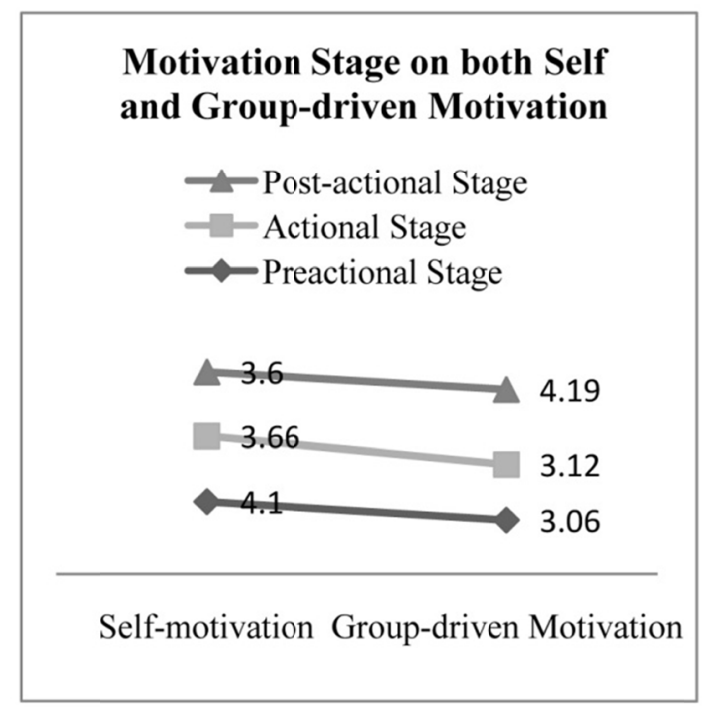

Diagram 3. Three stages of self and group-driven motivations' participants

\section{Discussion}

\subsection{The Factors Influencing Self and Group-Driven Motivation}

According to the results, there are some factors influencing self and group-driven motivation. Those factors are related to learning situation involving environment and status of English and affective factors of the participants.

\subsubsection{English as Foreign Language or EFL}

The status of English in Indonesia can be the most influencing factor. English itself is EFL in Indonesia which means the participants slightly use English in communication. Then, pronunciation and pragmatic, those aspects that give an important role in learning English are difficult. However, learning English naturally is very significant to the success of it. Brown (2007) states that the learners who learn the target language need much more effort to be fluent in target language especially English as a foreign language which has rarely contact to the community. The need of learning English is not only in the form of a structure of the language but also involves the most profound type of culture of the community which speaks English in daily activity. Therefore, this aspect can only be attained by interaction with the native. As a result, the participants in English Department may be well at grammar and structure construct than the verbal one. So that is why speaking English is rarely used and the situation in which speaking English is often used only happens in term of formal education. Emphasizing to the participants' achievement, having contact with the native speakers can accelerate the participants to be more successful in English. Besides, the participants can experience the social construct of English that can give a significant contribution to them to be more successful in every aspect of English (Brown, 2007).

On the other hand, this issue can be shown as an influencing factor toward English learners. This inhibition can become a stimulus toward EFL learners to take more effort to be successful. However, this effective factor works and is different in individuals. Therefore, this may not happen and indicate the participants is a higher motivation in learning it. The effort of learning English is more important because this can keep the participants learning English more and more rather than learning English as a choice. The motivation itself, researchers tried to measure the participants' attitude toward learning English can be seen in the participants' effort. For example, they facilitate their English while taking English Department as their major. This is very simple but worth to consider as the first step in achieving the goal. Moreover, in this stage, the participants have generated the motivation into action. This case is the assimilation of desire, wishes and hopes, and opportunities which raise the goal setting. Those emerge the intention formation that will follow as well as initiation of intention enactment where the motivation finally shapes into action (Dornyei, 1998).

Locke and Latham (1990) in Dornyei and Otto (1998) state that the intensity of the motivation here means the effort of the participants in the learning English. It emphasizes a commitment by involving self-confidence and interest as well. Both of them become the components which give a positive collaboration to the participants in 
EFL learning. Dornyei (1994) argues that other components of social and pragmatics are needed to be regarded in the study of L2 motivation. In the past research of Gardnerian or Gardner's motivation construct, the components of L2 motivation tend to focus on social and pragmatic dimensions. According to Garnerd (2000\&2001) in Dornyei (2005) states that those two dimensions value the motivation which is derived from the participants' motive. Those motives motivate them in learning English. On the social construct, the participants' motive in learning English can be seen toward participants' attitude to the English community or native. On the other hand, pragmatic construct relates to the particular things that give benefit to the participants learning it in the future, such as gaining L2 proficiency, getting a better job, and the higher salary.

Moreover, the other aspects or components that emphasize the specific situation become a concern a part of Gardner's two motivations construct. There are three components; they are course-specific motivational components, teacher-specific motivational components, and group-specific motivational components (Dornyei, 1994). Whether the components are compatible or not with the participants of the learning situation, those components can significantly enhance or even inhibit the participants' motivation. According to those components, several factors influence the participants' motivation that needs to be classified. Those influencing factors are taken from the three components, but the researcher only observed course-specific and group-specific motivational components.

\subsubsection{Expectancy}

This component is one of the course-specific motivational components, refers to the perceived a probability of success. This is related to the participants' self-confidence and self-efficacy in learning situation. Self-confidence refers to a belief of the learners have to their ability to accomplish goal or task competently. This is one of the effective variables which influence the most to the learner in learning English. Basically, self-confidence is a self-concept that exists in the human mind which is aware of the ability or the competence to handle any obstacle in the task (Dornyei, 1994). This is possible that the barriers can be anything, such as self-esteem, anxiety, and fear. The participants who have low self-confidence tend to be passive in the classroom. Meanwhile, Clement in Dornyei (1994:277) states the self-confidence is a center of the motivational process of the learner and affects the process of L2 learning. He also defines that there are two components in the effective self-confidence. Those are the notion of the cognitive aspect of self-evaluation in L2 proficiency and the affective aspect (anxiety).

Table 5. The statement 1

\begin{tabular}{ccc}
\hline The statement numbers & The statements & The average scales \\
\hline S22 & I always get nervous if I have to speak English \\
to all my friends
\end{tabular}

In the table above, the statements indicate anxiety in learning English. The student's average scale for the S22 is 3.15 which slightly disagree. It is concluded that most of the participants have high self-confidence. By emphasizing the scale, the high self-confidence can lead to the self-motivated learner. However, this is too early to say that self-confidence only indicates self-motivated learner. Specifically, this component not only plays a role in self-motivated learner but also group-driven motivated learner surely in the right collaboration (Dornyei, 1994).

\subsubsection{Interest}

This is more likely intrinsic motivation, such as self-confidence. It comes from a participant's desire to know more about L2. This component is essential to the motivational process. As the explanation above, interest can be as the primary source in learning L2. The main source stimulus that is powerful gives a stable encouragement to the learner's behavior in learning L2. It positively influences the learner to be more active in achieving the goal and to be successful. However, in the term of the motivational stage, this variable is not precisely used as the action measurement since the effect of the participant's perceptivity toward classroom structure can fuel positive behavior. There are more powerful aspects or motivational forces that can encourage the participants in action or underlie the behavioral process in learning L2. 
Table 6. The statement 2

\begin{tabular}{ccc}
\hline The statement numbers & The statements & The average scales \\
\hline S4 & $\begin{array}{c}\text { I wish I could send a letter and chat on } \\
\text { Facebook with many foreign friends }\end{array}$ & 4.46 \\
\hline
\end{tabular}

From Table 6, those statements indicate the interest of the learner toward English. The average scales for those ranges from slightly agree to moderately agree. It can be said that most of the participants have an interest in English. Meanwhile, the rest of the participants have less interest or even none. This case may as well lead to other aspects which serve specific purpose why the participants learn English. The aspects of relevance will be elaborated below.

\subsubsection{Relevance}

This factor refers to the extent to which the participants' feeling (Dornyei, 1994). The feeling is linked to the important personal needs, values, or goals. The values and the needs of the participants are defined to the instruction in the learning situation. This is a term of material which finds in the classroom and this case occurs if the participants are instructed by a lecturer who can lead them to the same goals. This component coincides with instrumentality or state of being instrumental. Because of it, the participants tend to evaluate the value or condition of the course they get in the classroom even in the group discussion.

Table 7. The statement 3

\begin{tabular}{ccc}
\hline The statement numbers & \multicolumn{1}{c}{ The statements } & The average scales \\
\hline S12 & $\begin{array}{c}\text { I love having an individual assignment because it } \\
\text { allows me to finish the assignment on time rather } \\
\text { than in a group }\end{array}$ & 4.19 \\
\hline S36 & A group discussion is really a waste of time & 3.46 \\
\hline S28 & $\begin{array}{l}\text { I always look forward to going home earlier then } \\
\text { allow me to finish the group assignment as soon as } \\
\text { possible }\end{array}$ & 2.15 \\
\hline
\end{tabular}

Table 7 shows that only S36 is having a low scale, 2.15. This is opposite to S12 which the statement basically has the same point too. However, the participants tend to find an excuse to choose disagreement strongly rather than to go straight to the point. Regarding the learning style of the participants in learning English, this affective aspect is shown in S12. The mode of S12 is $53.84 \%$ of the participants are influenced by their affective factor especially their learning style that makes the participants prefer to do the group assignment individually rather than in a group.

Meanwhile, the scale of S12, S28, and S36 show inconsistency. In emphasizing the goal, a self-goal and a group goal, these phenomena can indicate that the participants elaborate two goals in both aspects, self and group task. Somehow, the need to complete the task as a group cannot be denied; even though, it is not relevant to the participants' learning style. According to Dornyei (2005, p. 122), Learning styles are;

...an appealing concept for educationalists because - unlike abilities and aptitudes - they do not reflect innate endowment that automatically leads to success. That is, styles are not yet another metaphor for distinguishing the gifted from the untalented but rather they refer to personal preferences. These preferences are typically bipolar, representing a continuum from one extreme to another (e.g., being more global vs. Being more particular) and no value judgment is made about where a learner falls on the continuum: One can be successful in every style position — only in a different way.

The relevancy of learning style can enhance the participants' motivation whether they are self or group-driven motivated learners. It means that the components can influence the participants in both terms according to what is more relevant and how big the positive impact is. The positive impact itself is gained by the participants to achieve their goal of learning English is. Moreover, the group-specific motivational components also play a role in enhancing the participants' motivation toward target oriented activity. The relevancy of goal-orientedness, norm and reward system, and group cohesion have also triggered a motivation in learning English (Dornyei, 1994, p. 278). 
Owning to Dornyei further, the group-specific motivational components give the intention to the group-driven motivated participants. In a group assignment, as the member of the group, the participants will see the goal of the group first. Then, they will facilitate their need for a process for achieving the goal. Four variables include the group-specific motivational component. They are goal-orientedness, norm and reward system, group cohesion, and classroom goal structure. However, there are three components that the researcher considered to be the factors influencing the participants' motivation.

\subsubsection{Goal-Orientedness}

This component has to do with the participants' goal as members of the group. In this case, the group's goal may not be different from other individuals. Sometimes, the goal is not as the same at all since the group is purposely formed. Originally, the goal is to finish the task together or cooperate to get a good grade. The individual goal is sometimes extremely different from group goals such as having fun. Moreover, the extent to which the participants are coordinated to pursue the goal is referred to as goal-orientedness (Dornyei, 1994). The participants seemingly find difficulty in coordinating the group goal-orientedness. At S12, the problem is about the extent of finishing the group task in a certain time that the problem is about compromising the group goals on completing the task. This goal-orientedness seems to be hard to attune by the participants. This is why the scale shows moderate agreement. Different from S28, S36 has a slight disagreement (Table 7). We can see that the scales are inconsistent. On the other hand, the participants differently see the goal-orientedness as irrelevant with their goal of learning English. This case relates to the relevance component which emphasizes the goal-orientedness.

\subsubsection{Group Cohesion}

This group-specific motivational component is related to the quality of the participants' relationship to the member of the group or even to the group itself. If the participants face the goal of the group, they tend to be responsible for contributing to achieving the goal. It characterizes the cohesive group that gives a strong influence over the participants by the group's goal-oriented norms and makes the participants are more motivated.

Table 8. The statement 4

\begin{tabular}{ccc}
\hline The statement numbers & The statements & The average scales \\
\hline S20 & I always do my group assignment with or without \\
& my group & 3.76 \\
\hline
\end{tabular}

Table 8 shows why the average of group-driven motivation's scale is low. The participants seem to have a low cohesion to the member of the group. This case can be the effect of the low self-confident participants expressing an opinion if they do but having a dissenting opinion. Those aspects can be the reason why the participants are moderately individually motivated. Moreover, the other proof of the participants is slightly connected to the members of the group are shown by the effort which the participants put to the action, for example, encouraging the members of the group to participate in decision-making or good timekeeping. Otherwise, some of the participants stay to be inactive in the group assignment. This can be seen in Table 9 below.

Table 9. The statement 5

\begin{tabular}{ccc}
\hline The statement numbers & The statements & The average scales \\
\hline S13 & I always let my friends to arrange our group & 3.8 \\
& assignment schedule & \\
\hline
\end{tabular}

\subsubsection{Learned Helplessness}

This component is often found in the L2 learning process. The variable of personal orientation, behavior, and belief affects the participants' motivation on the setting of performance goals. In this case, the helpless participants tend to be easily giving up on achieving goals. They prefer to be pessimistic than trying harder. As a result, the helpless participants usually seem as the passive learners (Dornyei, 1994). 
Table 10. The statement 6

\begin{tabular}{ccc}
\hline The statement number & The statement & The average scale \\
\hline S $8(-)$ & I sometimes daydream about dropping English & 5.12 \\
\hline
\end{tabular}

From Table 10, the participants moderately disagree about S8. To be sure, it proves that they have self-confidence that defines them more self-motivated than the learned helplessness learners. However, $23 \%$ of them chose to agree with the statement. The percentages of the scales are $11.5 \%$ of slightly agree, $7.7 \%$ of moderately agree, and $3.8 \%$ of strongly agree. However, the statement is not totally about dropping English. The quality of the frequency in the statement "sometimes" also influence the meaning which means the motivation of the participants can be changeable regarding the other specific aspects.

Additionally, two factors which influence the participants, EFL and learned helplessness, are specific components extrinsically and intrinsically influencing the participants in the learning situation. Regarding the status of English itself and the learners of English, English is uncommonly used in Indonesia that speaking it becomes uncomfortable. This reason can affect the effective factor of the English learners' behavior in the learning process. Both factors interrelate, and the relationship can become one of the causative factors in the learned helplessness of the participants.

\subsection{The Dominant Motivation Type between Self and Group-Driven Motivation of the Participants}

After determining the factors influencing both self and group-driven motivation, it comes down to which both motivation types are more dominant between self and group-driven motivation among the participants. But first, the three phases of the motivation of the participants are discussed to see their motivation phases. Both of those motivation stages have been calculated from all process of three phases of motivation without dividing them into two terms of motivation types and next into two terms motivation, self and group-driven motivation.

\subsubsection{Motivation Stage of the Participants}

The case can become the most regard to this study due to the motivation research is more complex research. The ideas of influential factors that give much effort or positively affect the participants in learning English have been subject to the rigorous research. This means the research about motivation is still growing. As we can see in Diagram 1, the ups and downs of the stages represent how the motivation stage of the participants is an accumulation. In the pre-actional stage, the participants were required to fill the questionnaire based on how they feel about it. In the first stage, it contains many statements providing the goal setting. The goal setting is needed as the presented motivation. The scale of the first stage shows 3.49 which means the participants slightly agree with the first state of motivation in the very first one. According to Dornyei $(1998$, p. 48), states there are three representations of the pre-actional process. Those representations of motivational influences are divided into goal setting, intention formation, and the initiation of intention enactment.

In the goal-setting process, it is made up of some variables involved from the feeling of the participants into English. How the learners of English have a strong desire to be successful in learning English and put some wishes and hopes through it. Besides, the opportunities also become the big account as the goal setting that is presented by fulfilling the need in the learning process. The opportunities that the participants gain can estimate how successful they are in learning. Then, the goal settings have been represented in mind, the participants form an intention formation to the goal setting. To achieve or succeed, the formation is produced by a learner into three categories. The first is an action plan. This action plan is figured out by regarding the goal that the participants want to achieve. The second one is a goal or assigned task. As the basis of the action plan, the assigned task needs a commitment to the compliance. This is the third that becomes the determined action for the participants in the first stage of motivation. Besides the initiation of intention enactment is also involved in the process.

From Diagram 1, the figure of the action stage is 3.36 which mean the participants slightly disagree. It can be said that they are less motivated in the second stage. Emphasising the case, they tend to be more motivated in the first stage. In other words, the participants in the action stage failed to persist the progress in the first stage. However, the action stage consists of several executive motivational influences which are an appraisal, subtask generation and implementation and action control (Dornyei \& Otto, 1998, p. 47). Those seem to be as same as with the first stage, but this stage emphasizes the application of the actional stage in the learning condition. The representation of the task, barriers, and commitment are the most influential variable in this stage. The actional outcome can be opposite with what have expected in the first stage. This case involves many aspects that 
individually different.

Different from the first and second stage, the last scale of the third stage is higher. From the diagram above, we can see that the scale is 3.92 which mean the participants are identified to be moderately agreed. This can be concluded that the learners are more motivated in the post-actional stage than both stages. In the post-actional stage, there is two variables influence on the stage. They are terminated by an action and achieved the goal. Those variables give a different determining action in the last stage. Whether the participants are satisfied with the whole motivated behavioral process or not, they have been considered in previous stages. Then, those variables will be evaluated by three components of the post-actional process. The components are forming causal attributions, dismissing intention and further planning, and elaborating standard and strategies.

In the post-actional stage, the participants agree to some statements which have proposed by the researcher in the post-actional questionnaire. During this phase, the participants will compare initial expectancies and plans of action to how they turned out those variables in reality and formed causal attributions about the extent of the intended goal that has been reached (Dornyei and Otto, 1998). Then they will eliminate their standards in the second phase and elaborate it for the further planning. Such an inventory, the next process may have a different evaluation as before. The dynamic motivation occurs if all strategies are out of the first experience. As a human, a learner will always experience a new thing than evaluate the mistake over and over.

Heckhausen \& Kuhl in Dornyei \& Otto (1998) state that there are six self-regulatory strategies affect the motivational influence approach, the motivational forces which emerge after experience the actional stage can be affected positively and negatively to the learners. They are selective attention, encoding control, emotion control, motivational control, environment control, and parsimony of information processing. Here, the emotion control can become one factor influencing the participants' motivation progress on the actional stage. This emotion control can be categorized as the affective factors which personally influence the participants. Their feeling can have control to manage them from the failure or harm if they come to the intention. This inhibition of the emotional state can make the participants are less motivated to be successful.

Moreover, the fluctuated motivation progress of the participants can be a representation of the relevance toward the goals; it can be personal or group goals. This is one of the course-specific motivational components that can be seen in the learning task, the teaching materials, teaching methods, etc. It concerns the participants' individuals feeling toward the instruction is related to the personal practical advantages. It is as same as the instrumental motivation at the level of learning situation (Dornyei, 1994). Moreover, Pribadi (2000) states that the learners who have a high instrumental motivation tend to be more active than the integrative motivated learners. The low scale of the actional stage on the diagram above indicates that the participants were seeing the course content seem to be not conducive to achieving their goal. This case occurs before the action, the initiation of intention enactment level of the pre-actional stage. It evaluates the means and resources, intention, and start condition as to launch an action. If the means and resources are none in the situation of the classroom, the subtask generation and implementation of the participants on the action is given up.

\subsubsection{Self and Group-Driven Motivation of the Participants}

The participants' motivation was divided into two types, self and group-driven motivation. The analysis of both motivation types had been done to see how the self and group-driven motivation scales of the participants toward target oriented activity is. The total scale of each motivation types was calculated to find the average scale. Each motivation' scale of both types is shown in diagram 2.

From Diagram 2, those scales are gained by dividing the statement of the questionnaire into two categories of motivation, each scale of the statements are calculated. Then, as we can see above, the scale of the self-motivation toward participants is higher than group-driven motivation. The range of the motivation types is 0.60. It means that the participants experience the self-motivated learning more than group-driven motivated learning. In the most statements within the questionnaire which indicate the self-motivated notion are agreed. However, the scale of the statements' number of 26 and 30 shows that most of the participants choose moderately agree to agree strongly. This can strongly indicate that the participants' motivation progress on self-motivation is more dominant than the group-driven one.

However, the range between both of self and group-driven motivated participants is only 0.60 which means low. Moreover, the higher scale, self-motivation, shows the scale level of between slightly disagrees to moderately agree in the Likert scale. Then, it is slight disagreement for group-driven motivation. The range of both motivations' scale indicates that the level of both motivations have a contribution to the participants' motivation that can be said that both motivations are interrelated or even interdependent. There are some statements in the questionnaire that show the inconsistent level of the participants between self and group-driven motivation. They 
are shown in the two tables below.

Table 11. The statement 7

\begin{tabular}{ccc}
\hline The statement number & The statement & The average scale \\
\hline S23 & Studying English with group is not enjoyable at all & 2.3 \\
\hline
\end{tabular}

Table 12. The statement 8

\begin{tabular}{ccc}
\hline The statement number & The statement & The average scale \\
\hline S25 & I always feel very much at ease if I have to speak English with my & 4.23 \\
& friends accompanying me & \\
\hline
\end{tabular}

From two tables of Table 11 and Table 12. the interdependent motivational relationship among the participants can be conditional. From those statements are concerning the similarity of the target value among participants as the member of the group. i.e., doing a group assignment (compare with goal-orientedness in letter e). Moreover, in a certain condition the goal becomes conditional. it depends on the individuals. If the target will complete the task. he needs the same goal setting among the member of the group and this refers to the group cohesion. Furthermore, it can be said that the participants will prioritize their goal rather the group target. If the participants feel the instrumental components to be irrelevant, their integrative motive will enact. Therefore, there is slight chance that it makes to resemble what Dornyei concludes that:

As has been discussed earlier. extrinsic regulations should be internalised as much as possible to foster intrinsic motivation. Rewards and punishment (typically expressed in grades) should give way to group norms, which are standards that the majority of group members agree to and which become part of the group's value system Dornyei (1994. p. 278).

\subsection{The Self and Group-Driven Motivation Stages of the Participants}

After determining the motivation stage of the participants in the previous discussion. the next debate is to show the participants' motivation stage in both motivation types, self and group-driven motivation. The motivation progress of both motivation types is determined in Diagram 3.

From Diagram 3, we can see that both motivation stages are different. The self-motivated participants' scales in the three motivation stages are decreased. Even though the quarrel scale from the first phase to the last one appears only slightly. However, the scales lessen to the last step. It is entirely different from group-driven motivation.and the group-driven motivated learners tend to have good progress in the motivation stage. There must be several reasons why the motivation progresses in both motivation types are different. Some of them are respectably discussed as follow:

Motivation emphasizes the action sequence which projects how the behavior of learners including wishes. hopes. and desires are transformed into an action (Dornyei \& Otto. 1998. p. 47). That silly stuff which is to be motivational forces forms goal setting. The self-motivated participants with the goal setting are the learners who have high strengths. The unrealistic things are based on integrativeness. This integrativeness is more indicated by having a high self-efficacy, self-confidence, and opportunities. It means that self-motivated learners have a higher force in the first stage than the second and third scene. Therefore, the pre-actional stage of self-motivation is higher than other stages. actional and post-actional stage, as we can see in diagram 3.

Different from self-motivation, the group-driven motivation' average scale of the participants in the pre-actional stage is lowest than the self-motivation' pre-actional stage. We can see above that the scale of group-driven motivation in the first stage is 3.06. This means that most of the group-driven motivated participants are less motivated if they are given a task in a group assignment rather than making up the goal setting, the learners prefer to manage the group. This happens because the action sequence setting on pre-actional stage engages the goal setting of all members of the group. The adjustment of goal setting among the group leads to the environment control Anderman \& Maehr (1994) in Dornyei \& Otto (1998).

However, in the case of the actional stage, the group-driven motivated participants' average scale increases. This is higher than pre-actional one. This happens if the participants in the enactment process are successful in engaging the group goal setting, adjust intention formation of the group, and then make up the intention. Those 
processes influence the action and the environment control by the group. Furthermore, Dornyei (1994. p. 279) also states that:

The cooperative goal structure is more potent in promoting intrinsic motivation (in that it leads to less anxiety, greater task involvement, and more positive emotional tone), positive attitudes toward the subject area, and a caring cohesive relationship with peers and with the teacher which has been analyzed by Julkunen that the effect of the goal structure in L2 motivation and his result supported the superiority of cooperative learning.

Other factors which make the motivation dynamic are the requirement to the extrinsic motivation. It means that if the participants who are self-motivated learners meet some requirements in the classroom structure needed to do such as group assignment. The demand can be learning strategy which is used by lecturers for their students. e.g.. group assignment. In order to achieve the standard of the classroom, the participants will obligate the task and make it the priority. This case affects their intrinsic interest as the result of focusing on the standard what has become the learners' duty in the classroom (Dornyei, 1994). Conversely, if the learners have achieved their goals but the class's obligations interfere with them, they will forget the goal and begin to reach the classroom classification.

Goal setting can have exceptional importance. It means that the degree of motivation of individual is affected by how much the goal worths. A participant can set his/her goal in learning L2 as the most important such as gaining a job, communicating with a new environment which ESL, etc. Meanwhile. the goal setting can affect the effort of the learner in learning as long as the goals are still worth to achieve in the future. If the value of the goals is only in the short term progress such as a good grade, this will affect the learners and become the factor inhibiting their motivation in the future. Obviously, this can make the learners' motivation fluctuates in certain things.

\section{Conclusion}

The conclusion of this research answers the research questions. The first research question is asking the factors influencing self and group-driven motivated participants on target oriented activity. Four factors are determined by the researchers to be the influencing components to self and group-driven motivation of the participants. First, the status of English in Indonesia is a salient aspect which considerably influences the participants in learning English. Second factors are expectancy, interest, and relevance. Those are from course-specifics motivational components. Third factors would be group-specific motivational components that involve two components; goal-orientedness and group cohesion. The last but not least is learned helplessness. This effective factor that is salient to the learners especially English Departments students 2015-2016 academic year Universitas Jember negatively affects their behavior toward learning process.

The second research question is which motivation types are more dominant among the participants between self-motivated or group-driven motivated participants. The result of the average scale between self and group-driven motivation are 3.85 for self-motivation and 3.25 for group-driven motivation scale. The scale shows that the participants are more self-motivated than group-driven motivated. However, the scale range is only 0.60 which indicates between self and group-driven motivation on the participants have an interrelated or even interdependence relationship. This relationship is the affecting of subjective values and norms as the more significant force to the participants.

The last research question is how the motivation stage progress toward target oriented activity is. In the three phase's motivation progress, the scale is higher in the pre-actional stage than the actional stage. However, the post-actional stage has the higher scale than both stages. On the other hand, the motivation progress of the participants which have been divided into both motivation types, self and group-driven motivation, reveals a downward scale for self-motivation and an upward scale for group-driven motivation. This case proves that the group-driven motivation progress which fluctuates of the upward stage from pre-actional to actional then post-actional stage can develop participants' motivation for the long-term learning process. This can impact positively better participants' motivation but still need to consider the other factors which can inhibit and enhance the motivational force.

Throughout these results, it is concluded that we need to pay more attention to the motivation type of the learners in learning L2 to motivate them to be successful. By doing this research, it is assumed that the motivation of English Department students in Grammar \& Structure 03 of A class is as dynamic. It fluctuates in particular condition based on individuals. Besides, many aspects need to consider in the learning situation. So for a better result in doing the same field research, it is suggested to provide more significant aspects which are to be the primary focus of doing motivation research especially the direct recording of how the observation is done. 


\section{References}

Anjomshoa, L. (2015). The Importance of Motivation in SLA. International Journal on Studies in English Language and Literature, 3(2), 126-137.

Bertram, D. (2008). Likert Scales: Are the meaning of life. Retrieved from http://poincare.matf.bg.ac.rs/ kristina/topic-dane-likert.pdf

Bin-Tahir, S. Z., \& Rinantanti, Y. (2016). Multilingual Lecturers' Competence in English Teaching at the University of Iqra Buru, Indonesia. Asian EFL Journal, 5, 79-92.

Brown, H. D. (2007). Principles of Language Learning and Teaching (5th ed.). USA: Pearson Education. Inc.

Dollah, S. (2016). The effect of self-esteem. anxiety. and gender on oral communication of EFL learners (penghargaan diri. kecemasan. dan jenis kelamin terhadap komunikasi lisan pebelajar bahasa inggris sebagai bahasa asing). Sawerigading, 15(3), 349-360.

Dörnyei, Z. (2005). The Psychology of the Language Learner: Individual Differences in Second Language Acquisition. Mahwah, New Jersey: Lawrence Erlbaum Associates. Inc.

Dörnyei, Z. (2008). Motivation and Motivating in the Foreign Language Classroom. The Modern Language Journal, 78(3), 273-284.

Dörnyei, Z., \& Otto, I. (1998). Working Paper in Applied Linguistics: Motivation in Action: A Process Model of L2 Motivation (Vol. 4. pp. 43-69). London: Thames Valley University.

Kostoulas, A. (2016). On Likert Scales. Ordinal Data. and Mean Values. Retrieved from http://achilleaskostoulas.com/2013/02/13/on-likert-scales-ordinal-data-and-mean-values/

Krashen, S. (2013). Second Language Acquisition: Theory Applications and Some Conjectures. Mexico: Cambridge University Press.

Nicholson, S. J. (2013). Influencing Motivation in the Foreign Language Classroom. Journal of International Education Research, 9(3), 278-286. https://doi.org/10.19030/jier.v9i3.7894

Patahuddin, P., Syawal, S., \& Bin-Tahir, S. Z. (2017). Investigating Indonesian EFL Learners' Learning and Acquiring English Vocabulary. International Journal of English Linguistics, 7(4), 128-141. https://doi.org/10.5539/ijel.v7n4p128

Salikin, H., Bin-Tahir, S. Z., \& Emelia, C. (2017). The Higher Achiever Students' Strategies in English Learning. Modern Journal of Language Teaching Methods, 7(11), 79-95.

Salikin, H., Bin-Tahir, S. Z., Kusumaningputri, R., \& Yuliandari, D. P. (2017). The Indonesian EFL Learners' Motivation in Reading. English Language Teaching, 10(5), 81-90. https://doi.org/10.5539/elt.v10n5p81

Saville-Troike, M. (2006). Introducing Second Language Acquisition. New York: Cambridge University Press.

Tahir, S. Z. B., \& Hanapi, H. (2017). Lecturers' Method in Teaching Speaking at the University of Iqra Buru. International Journal of English Linguistics, 7(2), 73. https://doi.org/10.5539/ijel.v7n2p73

Vygotsky, L. S. (1978). Mind in Society: The Development of Higher Psychoogical Processes. Massachusetts London: Harvard University Press Cambridge.

White, L. (2003). Second Language Acquisition and Universal Grammar. New York: Cambridge University Press.

Yule, G. (2010). The Study of Language (4th ed.). USA: Cambridge.

Zareian, G., \& Jodaei, H. (2015). Motivation in SLA: A State of the Art Article. International J. Soc. Sci. \& Education, 5(2), 295-308.

\section{Copyrights}

Copyright for this article is retained by the author(s). with first publication rights granted to the journal.

This is an open-access article distributed under the terms and conditions of the Creative Commons Attribution license (http://creativecommons.org/licenses/by/4.0/). 